\title{
Scale and Size Effects on Dynamic Response and Damage of Glass/Epoxy Tubular Structures
}

\author{
M. Tarfaoui ${ }^{1^{\star}}$, P.B. Gning ${ }^{1}$, P. Davies ${ }^{2}$, F. Collombet $^{3}$ \\ 1 ENSIETA / MSN, 29806 Brest, France \\ 2 IFREMER Brest Center, 29280 Plouzané, France \\ 3 LGMT-PRO2COM, IUT Paul Sabatier, 31077 Toulouse, France \\ *: Corresponding author : tarfaomo@ensieta.fr
}

\begin{abstract}
:
The impact behavior of composite materials has been extensively studied but interest has been centered on flat plates. For underwater applications, thick composite cylinders are employed and several questions must be addressed concerning the influence of accidental impact. The aim of this work is to study the dynamic response of tubular structures. Such structures find many applications but the damage upon impact is not taken into account during their dimensioning. However, at the time of their handling or in service the damage introduced by accidental impact can compromise their capacity to fulfill their function. The cylinders are thick and consist of epoxy matrix and glass fiber reinforcement. After having observed the nature of the damage related to the static and dynamic loading, the scale and size effects on dynamic response and damage are examined. The studies reveal that the dynamic responses show a satisfactory correlation with predictions based on rules of similitude.
\end{abstract}

Keywords: filament winding $\bullet$ impact $\bullet$ damage $\bullet$ scale effect $\bullet$ size effect 


\title{
SCALE AND SIZE EFFECTS ON DYNAMIC RESPONSE AND DAMAGE OF A GLASS/EPOXY TUBULAR STRUCTURES
}

\author{
M. Tarfaoui ${ }^{1 *}$, P.B. Gning ${ }^{1}$, P. Davies ${ }^{2}$, F. Collombet ${ }^{3}$ \\ ${ }^{1}$ ENSIETA / MSN, 29806 Brest, France \\ ${ }^{2}$ IFREMER Brest Center, 29280 Plouzané, France \\ ${ }^{3}$ LGMT-PRO'2COM, IUT Paul Sabatier, 31077 Toulouse, France
}

\begin{abstract}
The impact behavior of composite materials has been extensively studied but interest has centered on flat plates. For underwater applications thick composite cylinders are employed and several questions must be addressed concerning the influence of accidental impact. The aim of this work is to study the dynamic response of tubular structures. Such structures find many applications but the harmfulness of impact is not taken into account during their dimensioning. However, at the time of their handling or in service the damage introduced by accidental impact can compromise their capacity to fulfill their dedicated function. The cylinders were thick and consist of epoxy matrix and glass fiber reinforcement. After having observed the nature of the damages related to the static and dynamic stresses [1], we propose to examine the scale and size effects on dynamic response and damage. The studies reveal that the dynamic responses in deformation spread out perfectly according to the rules of similarities. These results are validated by the predictions obtained from analytical solutions.
\end{abstract}

KEYWORDS: Filament winding, Impact, Damage, Scale effect, Size effect.

\section{INTRODUCTION}

Composite materials with organic matrix resins are increasingly being used for marine and underwater applications. There are many advantages of composites in the marine field: low weight, corrosion resistance, and stiffness. The main load on such structures is hydrostatic pressure, which increases with immersion depth, but damage tolerance is also a key parameter. Impact of composite laminates has been extensively studied. However, the majority of the published work has focused on impact of plates rather than curved structures. Alderson and Evans [2,3,4] presented a comparative study of damage mechanisms in thin filament wound E-glass/epoxy tubes under static and dynamic loading. Tests consisted of quasi-static indentation and low speed single bounce impacts with high energy levels on floor and cradle-supported cylinders. They noted the importance of limit conditions on the delaminated area. Bülent-Doyum et al. [5] investigated the detection of damage after low speed falling weight impact on thin E and S-glass wound cylinders. Kim et al. [6] investigated the effect of curvature on the dynamic response of cylindrical composite panels using finite element analysis and they showed that slightly curved panels respond to impact in the same way as flat plates but the contact force increases with the curvature. The delaminated area is more important in impacted panels than in flat plates at equivalent impact energies. Krishnamurthy et al. [7] performed a parametric study of the impact response of laminated cylindrical composite shells using finite element methods, but their results were not validated by experimental studies. This study showed that the projectile velocity has a more important influence than the projectile mass in increasing contact force during impact. Gning et al. [1] presented experimental observations on damage development in thick

\footnotetext{
*tarfaomo@ensieta.fr
} 
composite tubes under impact loading and influence on implosion pressure. Kistler et al. [8] presented an experimental and numerical study of accidental impact on cylindrically curved carbon/epoxy composites representative of aircraft structures. The influence of several parameters both on projectile and target behavior was compared numerically, but damage induced by impact was not predicted. Evans et al. [9] obtained a good distribution of shear stresses through the thickness from FE modeling of quasi-static punching tests, confirming experimental observations.

Christoforou et al. [10] took an analytical to the solution of the scale effects problem. Although the elastic response (analytical and experimental) of the cylinders is related to the scale effects, the authors do not draw any conclusion on the influence of the scale in the dynamic damage of the composite tubes. Davies [11] does not observe a particular slope due scaling at the implosion tests of the composite tube. The laws of scale called laws of similarity are presented by Dormegnie [12] in the case of impact on laminated composite structures. Qian and Swanson [13], in a similar step, present analytical and experimental studies of the scale effects at the impact on laminated plates and thin tubes with reinforcements of carbon and epoxy matrix. The studies reveal that the dynamic responses in deformation spread out perfectly according to the rules of similarity for energies lower than the thresholds of formation of damage. These results validate the predictions obtained from analytical solutions.

It comes out from this assessment that the detailed study of the damage of thick glass/epoxy cylinders has received very little attention from the research community. There is a need to analyze the influence of the dynamic interaction cylinder/projectile on the initiation and the evolution of the damage. It is desirable to control the tolerance to damage of the cylindrical composites for their optimal exploitation. The control of the scales effects on the composite tubular structures behavior can result in important benefits at the time of the design of the underwater machines. Note also that few known studies were conducted on the causality scale/damage in impacted composite tubular structures.

\section{MATERIALS}

The material used in this study consists of 2400 Tex E-glass fibers impregnated with an epoxy matrix. Samples were made by helical wet filament winding of the E-glass yarns around a steel mandrel oriented at $\pm 55^{\circ}$ with respect to the mandrel axis.

\section{The Specimens}

By taking as reference the Mat 3 cylinders, Mat4 makes it possible to observe the effect of the curve, by a factor 3 , on the damage for the same wall thickness. Mat5 makes it possible to study the scale effects by the same factor comparatively with Mat3 (figure 1a). Table 1 shows the specifications of the various test tubes in connection with figure $1 \mathrm{~b} .(\mathrm{r}, \theta, \mathrm{z})$ and $(1,2,3)$ are the reference marks associated with the tube and the ply, respectively. All the tubes in this study are considered thick and short.

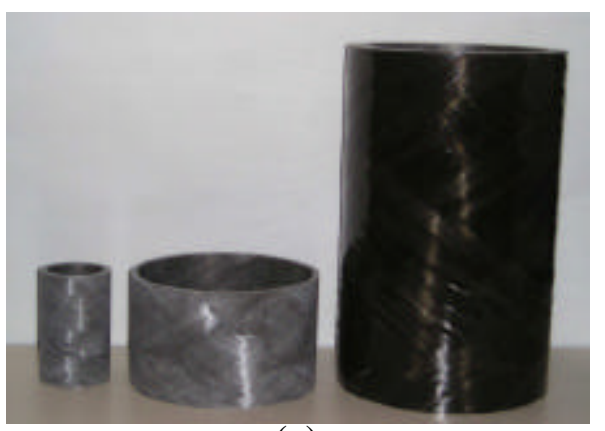

(a)

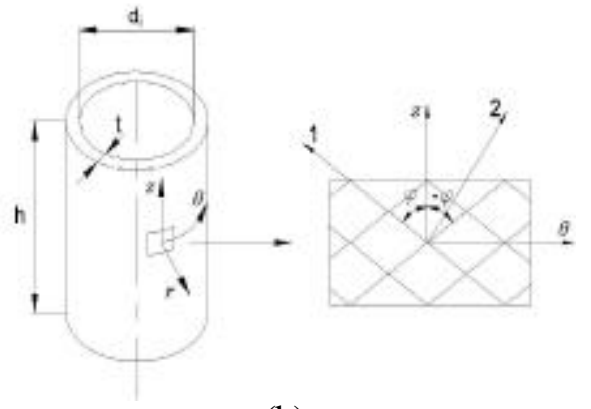

(b)

Figure 1. (a) Samples Mat3, Mat 4 and Mat5 and (b) Tube coordinates and notations. 


\begin{tabular}{|l|c|c|c|c|}
\hline Material & $\begin{array}{c}\text { Internal diameter, } \\
\mathrm{di}(\mathrm{mm})\end{array}$ & $\begin{array}{c}\text { Wall thickness, } \\
\mathrm{t}(\mathrm{mm})\end{array}$ & $\begin{array}{c}\text { Tube length, } \\
\mathrm{h}(\mathrm{mm})\end{array}$ & $\begin{array}{c}\text { Stacking } \\
\text { sequence }\end{array}$ \\
\hline Mat3 & 53 & 6 & 110 & {$[ \pm 55]_{10}$} \\
\hline Mat4 & 159 & 6 & 110 & {$[ \pm 55]_{10}$} \\
\hline Mat5 & 159 & 18 & 330 & {$[ \pm 55]_{31}$} \\
\hline
\end{tabular}

Table 1. Geometry and fiber mass fraction of the samples, standard deviation in brackets.

\begin{tabular}{|l|c|c|c|}
\hline Material & $\begin{array}{c}\text { Fiber mass } \\
\text { fraction }(\%)\end{array}$ & $\begin{array}{c}\text { Density } \\
\left(\mathrm{kg} / \mathrm{m}^{3}\right)\end{array}$ & $\begin{array}{c}\text { fiber volume } \\
\text { fraction }(\%)\end{array}$ \\
\hline Mat3 & $72(0,9)$ & 1935 & 55 \\
\hline Mat4 & $71(1,1)$ & 1924 & 54 \\
\hline Mat5 & $72(0,4)$ & 1939 & 55 \\
\hline
\end{tabular}

Table 2. Characteristics of the specimens.

The fiber mass fraction was determined by calcinations of the resin in samples from tubes, heated at $600^{\circ} \mathrm{C}$ for $2 \mathrm{~h}$ that indicated a fiber volume fraction of the three specimens. Void content was measured by image analysis to be around $6 \%$ as shown in Table 2. Mechanical characteristics of Eglass/epoxy ply $0^{\circ}$ was determined using micro-mechanics (Table 3 ). Tables 4 and 5 compare the elastic and failure values of the characteristics drawn from relations of micromechanics to those resulting from previous experimental work made in IFREMER/Brest [14]. One notes a satisfactory prediction of the value of the modules by micromechanics in table 4 . Indeed, the experimental techniques allow a reliable measurement of the elastic properties of the composite tubes [15]. On the other hand, the measurement of the failure values is more delicate. The failure of the specimens taken from the cylinders is not sufficiently representative of their ultimate behavior, which explains the relatively important variations in Table 4.

\begin{tabular}{|l|c|c|c|c|c|}
\hline Characteristics & $\mathrm{E}_{1}(\mathrm{GPa})$ & $\mathrm{E}_{2}(\mathrm{GPa})$ & $\mathrm{G}_{12}(\mathrm{GPa})$ & $v_{12}$ & $v_{23}$ \\
\hline Micromechanics & 46,6 & 13,3 & 5 & 0,27 & 0,32 \\
\hline Experimental & 49,5 & 15,9 & 5,6 & 0,26 & 0,34 \\
\hline
\end{tabular}

Table 3. Material elastic properties of a unidirectional E-glass/epoxy lamina

\begin{tabular}{|l|c|c|c|c|c|}
\hline Characteristics & $\mathrm{X}_{\mathrm{t}}(\mathrm{MPa})$ & $\mathrm{X}_{\mathrm{c}}(\mathrm{MPa})$ & $\mathrm{Y}_{\mathrm{t}}(\mathrm{MPa})$ & $\mathrm{Y}_{\mathrm{c}}(\mathrm{MPa})$ & $\mathrm{S}_{\mathrm{lt}}(\mathrm{MPa})$ \\
\hline Micromechanics & 1470 & 888 & 66 & 99 & 66 \\
\hline Experimental & 1200 & 600 & 35 & 12 & 70 \\
\hline
\end{tabular}

Table 4: Laminate ultimate strengths of a unidirectional E-glass/epoxy lamina [25]

\section{Quality Control}

Three types of controls are carried out in order to ensure the good quality of the tubes used. These checks relate to the geometry, the treatment of materials and the quality of filament winding. Table 5 shows the results of the dimensional check carried out on the tubes. Compared with the dimensions specified in Table 1, the recorded values and their dispersions are suitable for products manufactured by filament winding in an industrial setting.

\begin{tabular}{|l|c|c|}
\hline Material & Thickness $(\mathrm{mm})$ & Average $\mathrm{Tg}\left({ }^{\circ} \mathrm{C}\right)$ \\
\hline Mat3 & $5,8(0,12)$ & $162(1)$ \\
\hline Mat4 & $5,9(0,2)$ & $159(1)$ \\
\hline Mat5 & $18,4(0,3)$ & $160(1)$ \\
\hline
\end{tabular}

Table 5. Metrological control and measurements of $\mathrm{Tg}$ 


\section{IMPACT BY FALLING WEIGHT}

As the speed of immerged objects is often around $1 \mathrm{~m} / \mathrm{s}$, the falling weight impact set-up is the most appropriate apparatus to reproduce low energy impacts that may occur in underwater applications in service or during handling. The objective is to put forward the scale effects in the damage mechanisms of the composite cylinders under dynamic loading.

\section{The Experimental Setup}

Figure 2 shows a height drop tower from which a steel hemispheric nose projectile weight is released. From that height the projectile can reach speeds up to $8 \mathrm{~m} / \mathrm{s}$ with maximum impact energy of $50 \mathrm{~J}$ for Mat3 and Mat4 and $1350 \mathrm{~J}$ for Mat5. An ant rebound device allows only a single impact. The projectile is $150 \mathrm{~mm}$ long and is equipped with a piezoelectric accelerometer fixed in the tip near the contact point. The guide rails allow the middle of the tube sample, placed in a semi-cylindrical cradle, to be impacted. Two optical sensors with photodiodes just above the impact point provide the incidental velocity of the projectile. The test data is recorded by a Nicolet acquisition system with a frequency of $500 \mathrm{kHz}$. A CCD camera (FastCam APX) with a maximum recording rate of 120,000 images per second was used to check measured velocity and calculated displacements.
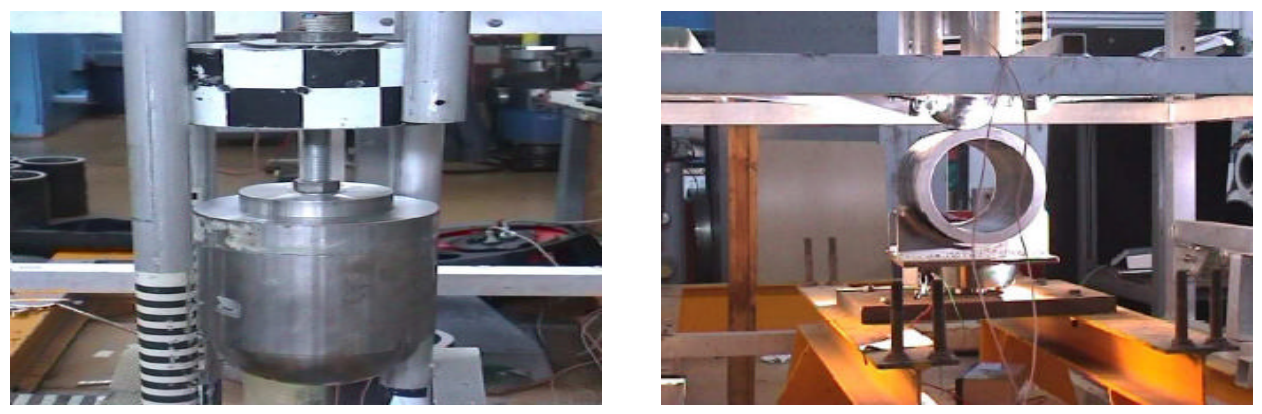

Figure 2. Instrumented drop weight set-up.

\section{Dynamic response}

Many impact levels have been tested. Impact load as a function of time $f(t)$, given by Equation (1), is proportional to the recorded acceleration signal $a(t)$ by the projectile mass $m_{0}$. The projectile tips displacement as a function of time $\mathrm{x}(\mathrm{t})$ is obtained by double integration of the acceleration signal. $\mathrm{v}_{0}$ represents the projectile velocity just before impact:

$$
\left\{\begin{array}{l}
f(t)=m_{0} a(t) \\
v(t)=\int_{0}^{T_{c}} a(t) d t+v_{0} \\
x(t)=\int_{0}^{T_{c}}\left(\int_{0}^{T_{c}} a(t) d t+v_{0}\right) d t
\end{array}\right.
$$

Contact force versus time measured by the accelerometer, plotted in Figure 3, shows significant noise. Fast Fourier Transformation of the contact force signal enabled the first Eigen mode to be identified at around $9 \mathrm{kHz}$. Recorded signals were, therefore, low-pass filtered with a cutoff frequency of $8 \mathrm{kHz}$. An example of filtered force response for a $2 \mathrm{~J}$ impact without damage is presented in figure 3. Filtering of the acceleration signal has no influence on the calculation of the impactor's displacements that stay identical. 


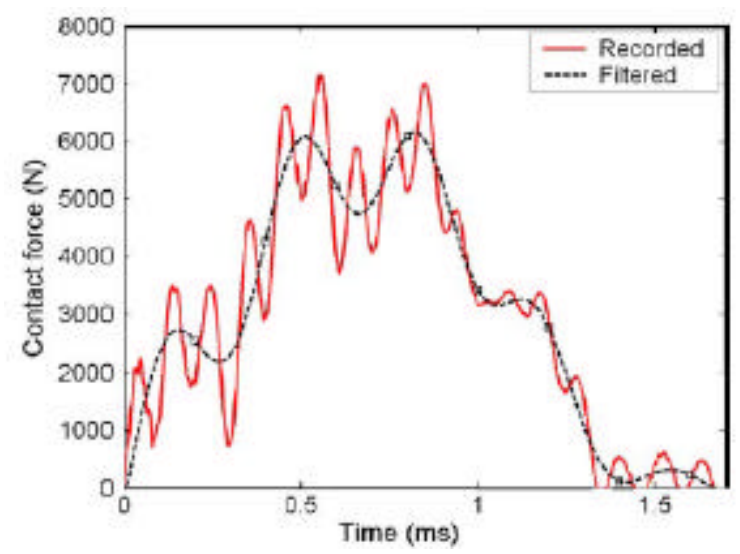

Figure 3. Recorded and filtered impact forces versus time for an elastic shock at $1.72 \mathrm{~m} / \mathrm{s}$.

\section{Observed Damage}

The damage observed is represented by a local crushing of the resin at the point of contact with the projectile (Figure 4). It is noted that beyond $9 \mathrm{~J}$, the resin surface cracks in concentric circles. No fiber failure is noted on the impacted face. Visual inspection makes it possible to observe the creation of damage in the thickness of the cylinder. One identifies limiting energy for the creation of the cracks and delaminations around $4 \mathrm{~J}$ for Mat3, then the damaged zone grows with the incidental energy.
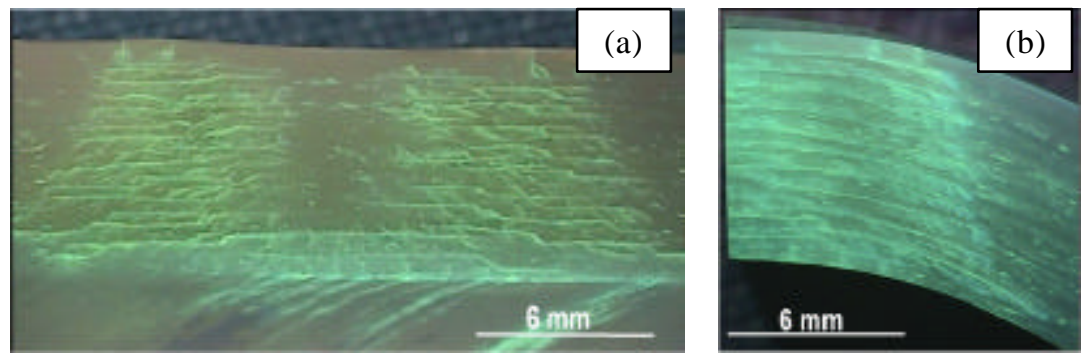

Figure 4. (a) Axial and (b) circumferential sections of cylinder impacted at $16 \mathrm{~J}$.

\section{SCALE EFFECTS}

After having observed the nature of the damages, we propose to examine the scale effects on the damage and mechanical behavior of the tubes. The characterization of the response to the impact is expensive and time consuming. It is necessary to mobilize several equipments to carry out the tests (ultrasound analysis of the samples, proceed to cutting and polishing, quantifying the damage...). The idea is to determine whether it is sufficient, for tubular geometries manufactured by filament winding, to study a small tube, without testing the real structures. The relevance of this reflexion becomes obvious in comparison with the economic considerations. In this part, the aim is to observe then quantify the scale effects on the dynamic response of the thick composites carried out by filament winding. It is a question of checking the applicability of the laws of similarity to the cylinders in glass/epoxy both for dynamic responses and damage.

\section{Rules of Similarity and Geometries}

For the analysis on various scales, the geometrical similarity known as the Cauchy rule is employed. This similarity is obtained by using the dimensional analysis and more particularly the theorem of $\pi$ of Vachy-Buckingham [16], which is based on the following assumptions:

- the model and the prototype consist of the same material,

- the model is a certified copy of the prototype,

- the dimensionless Cauchy number (Equation 2) remains constant; $\rho, v$ and $E$ represent the mass fraction, the velocity and Young modulus of the structure, respectively. 


$$
\frac{\rho v^{2}}{E}
$$

The characteristics of the prototype and the model evolve according to the scale factor, which is a number indicated by $\lambda$, as shown in Table 6 :

\begin{tabular}{|l|c|c|}
\hline \multicolumn{1}{|c|}{ Parameters } & Prototype & Model \\
\hline Acceleration & $\mathrm{A}$ & $\mathrm{A} / \lambda$ \\
\hline Strain & $\varepsilon$ & $\varepsilon$ \\
\hline Displacement & $\delta$ & $\lambda \delta$ \\
\hline Linear dimension & $\mathrm{L}$ & $\lambda \mathrm{L}$ \\
\hline Energy & $\mathrm{E}_{\mathrm{c}}$ & $\lambda^{3} \mathrm{E}_{\mathrm{c}}$ \\
\hline Time & $\mathrm{T}$ & $\lambda \mathrm{T}$ \\
\hline Velocity & $\mathrm{V}$ & $\mathrm{V}$ \\
\hline Strain rate & $\dot{\varepsilon}$ & $\dot{\varepsilon} \cdot \lambda$ \\
\hline Load & $\mathrm{F}$ & $\lambda^{2} \mathrm{~F}$ \\
\hline Mass & $\mathrm{M}$ & $\lambda^{3} \mathrm{M}$ \\
\hline
\end{tabular}

Table 6. Law of similarity.

\begin{tabular}{|l|c|c|c|}
\hline \multicolumn{1}{|c|}{ Parameters } & Prototype & Model & Model \\
\hline Scale factor $(\lambda)$ & 1 & 1 & 3 \\
\hline Cylinder & Mat3 & Mat4 & Mat5 \\
\hline Internal diameter $(\mathrm{mm})$ & 53 & 159 & $\lambda \delta$ \\
\hline Wall thickness $(\mathrm{mm})$ & 5,8 & 5,9 & $\lambda \mathrm{L}$ \\
\hline Tube length $(\mathrm{mm})$ & 110 & 110 & $\lambda^{3} \mathrm{E}_{\mathrm{c}}$ \\
\hline Stacking sequence & {$[ \pm 55]_{10}$} & {$[ \pm 55]_{10}$} & {$[ \pm 55]_{31}$} \\
\hline Fiber volume fraction $(\%)$ & 55 & 54 & 55 \\
\hline Tube mass $(\mathrm{kg})$ & 0,222 & 0,625 & 6,131 \\
\hline Projectile & P1 & P1 & P2 \\
\hline Projectile diameter $(\mathrm{mm})$ & 50 & 50 & 150 \\
\hline Projectile mass $(\mathrm{kg})$ & 1,6 & 1,6 & 43,1 \\
\hline Cradle & $\mathbf{B 1}$ & $\mathbf{B 2}$ & $\mathbf{B 2}$ \\
\hline Cradle diameter $(\mathrm{mm})$ & 104 & 225 & 225 \\
\hline
\end{tabular}

Table 7. Parameters of the scale and size effects.

Figure 5 shows the typical curves of the filtered responses in force and displacement versus time of Mat3 and Mat5. The tubes are impacted respectively at $11 \mathrm{~J}$ and $298 \mathrm{~J}$ following the conditions described previously. The responses of Mat5, presented by the graphs, are scaled according to the rules of similarity of Table 6 . It is noted that the forces involved reach equivalent maximum levels over corresponding durations. During the impact, the vibratory phenomena are more important for Mat5. Figure 5, representing also the displacement of the projectile, show a more important value on Mat5. It is interesting to compare the values of some dynamic responses between prototypes and models. Figure 6 shows the maximum contact effort reached, the maximum displacement as well as the duration of the interaction projectile/tube. The results obtained show in a general way a good coherence between them, thus validating the dimensional analysis within the Cauchy law for the dynamic responses of the impacts with damage on thick composite cylinders. 

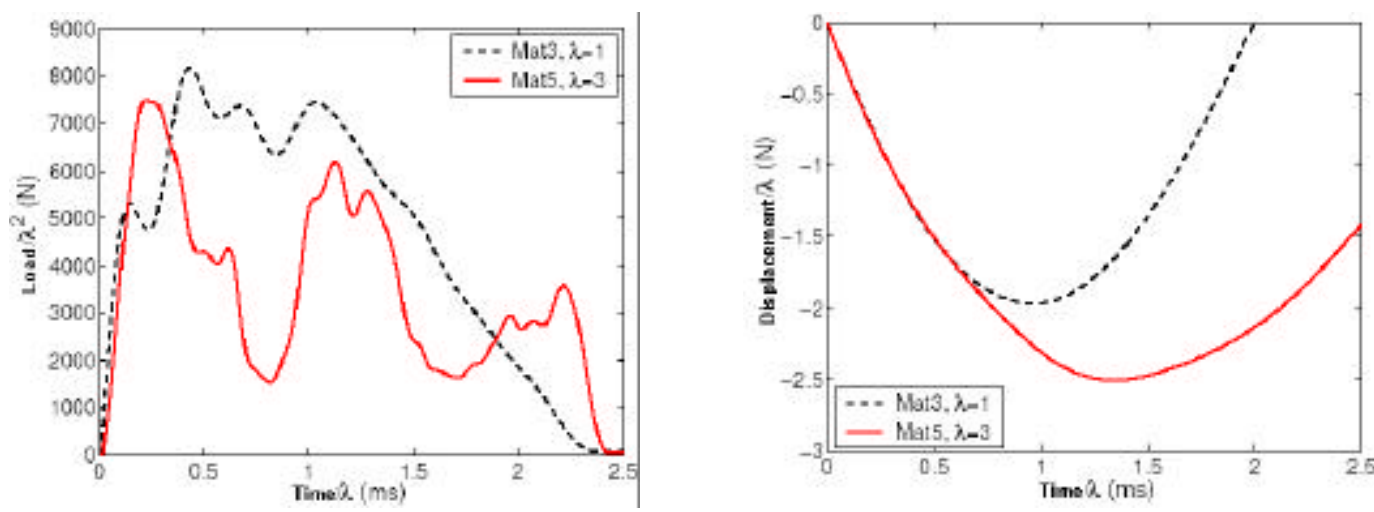

Figure 5. Curves of the filtered responses in force and displacement versus time.
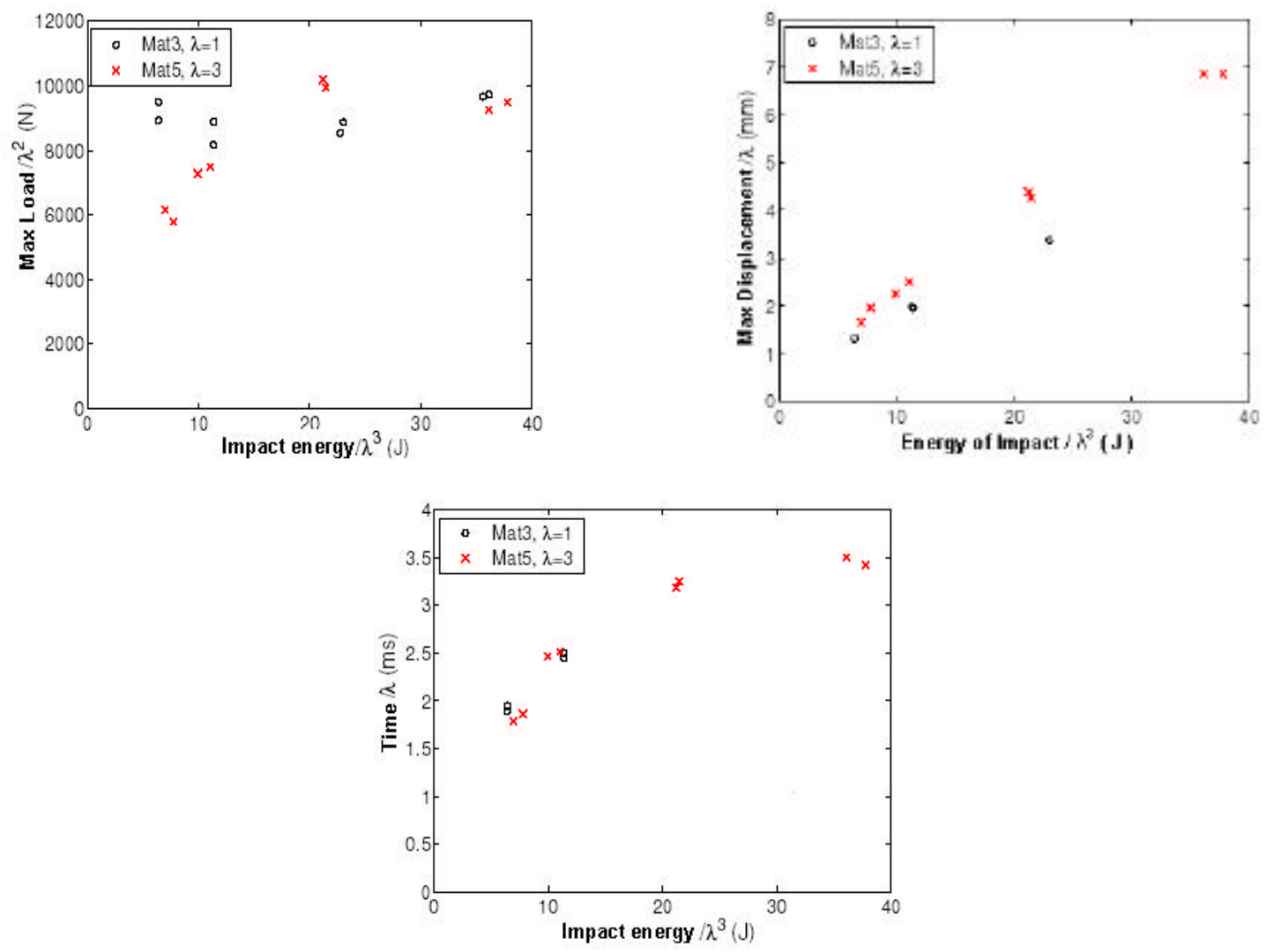

Figure 6. Evolution of the dynamic parameters.

\section{The Damage}

All the impacts on the prototypes and models are damaging. Figure 7 shows axial cutting of Mat 3 and Mat5 impacted tubes. The impact energy of Mat5 is about 27 times higher than those of Mat3. The identified damages are comparable to those discussed in the previous section. Figure 8 shows the evolution of the projected surface of delamination versus energy of impact for Mat3 and Mat5. Measurements for Mat5 are reported on the scale of the prototype on energy and delaminated surface. Dispersions in the results of Mat5 are more important than in Mat3. The curves have a positive slope. The Mat5 tubes present, on average, an evolution of projected surface 1.4 times larger than Mat3. The comparison of the cumulated surfaces presented on Figure 8, which represents their evolution according to incidental energy, shows that the cumulated surface of Mat5 has a slope three times higher. It appears that the larger the scale the more important the damage. This observation is identical to that of Qian and Swanson [17], which draw the same conclusion, following their study of the evolution of projected surfaces of delamination in thin sections of impacted carbon/epoxy structures. 

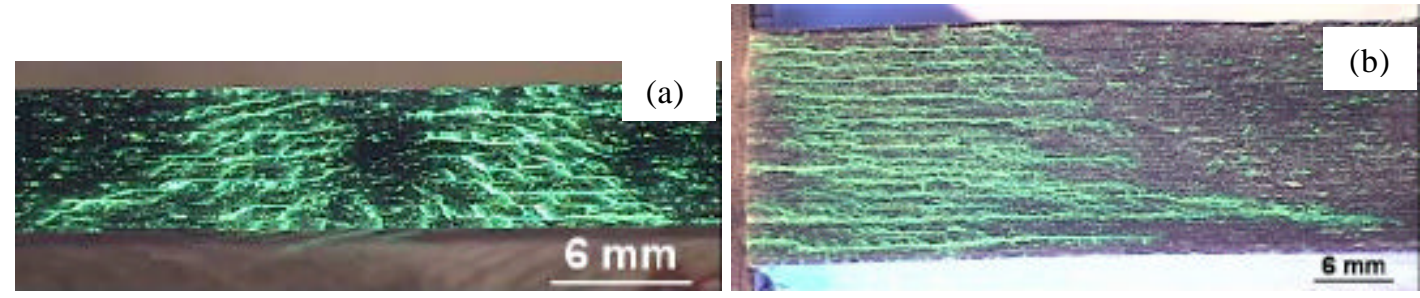

Figure 7. Axial cutting of the impacted zone (a) Mat3, $11 \mathrm{~J}$ and (b) Mat5, $268 \mathrm{~J}$.
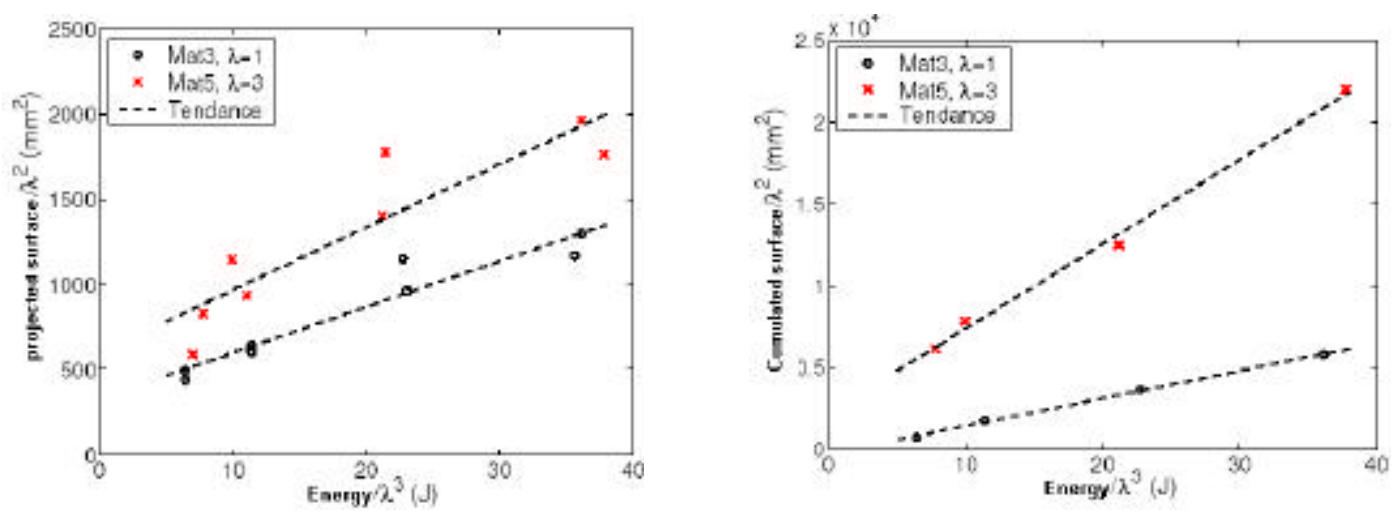

Figure 8. Comparison of dela minated surfaces for Mat3 and Mat5.

Note, with regards to these reports, the difficulties related to the realization of the tests and the differences observed in the measures in surfaces can be related to the effects of the residual stresses. Indeed, although Mat3 and Mat5 are considered thick, identical treatment, in comparison with the temperatures of vitreous transition, of a cylinder thickness $18 \mathrm{~mm}$ does not generate the same state of internal stresses as on a $6 \mathrm{~mm}$ thickness. Although the number of interfaces listed on Mat5 is 3 times higher than on Mat3.

The choice of the reorganization of the plies for the passage from the prototype to the model as well as the parameters of manufacture has a dominating importance. This makes debatable our decision to triple the number of interfaces instead of thickening the plies or to exploit the succession of the plies, which is technically more delicate to realize.

\section{SIZE EFFECT}

The analysis of the damage for the tests presented lets suppose a strong coupling between the material and the structure. In order to study the size effects on the damage, the Mat4 cylinders, having the thickness and length as Mat3 but with an internal diameter 3 times larger, were impacted. Their geometries as well as the characteristics of the tests are compared in table 7. Mat4 tubes are laid out in the B2 cradle. The two types of tubes are impacted with the same energies with the P1 projectile. This makes it possible to study the effect of size on the damage.
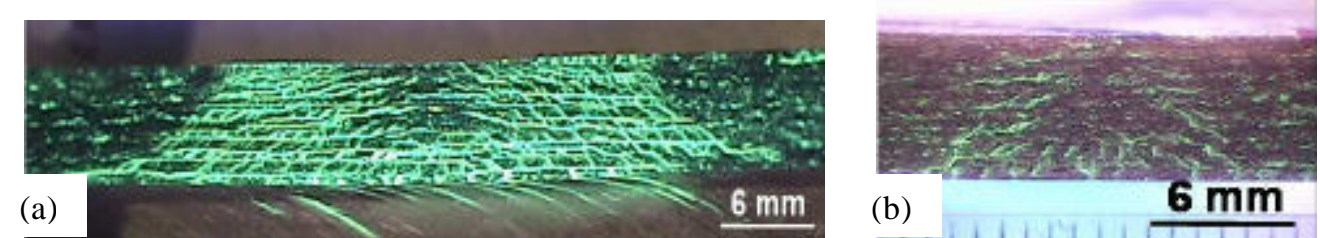

Figure 9. Axial cuttings of the zone impacted with $36 \mathrm{~J}$ on (a) Mat3 and (b) Mat4 

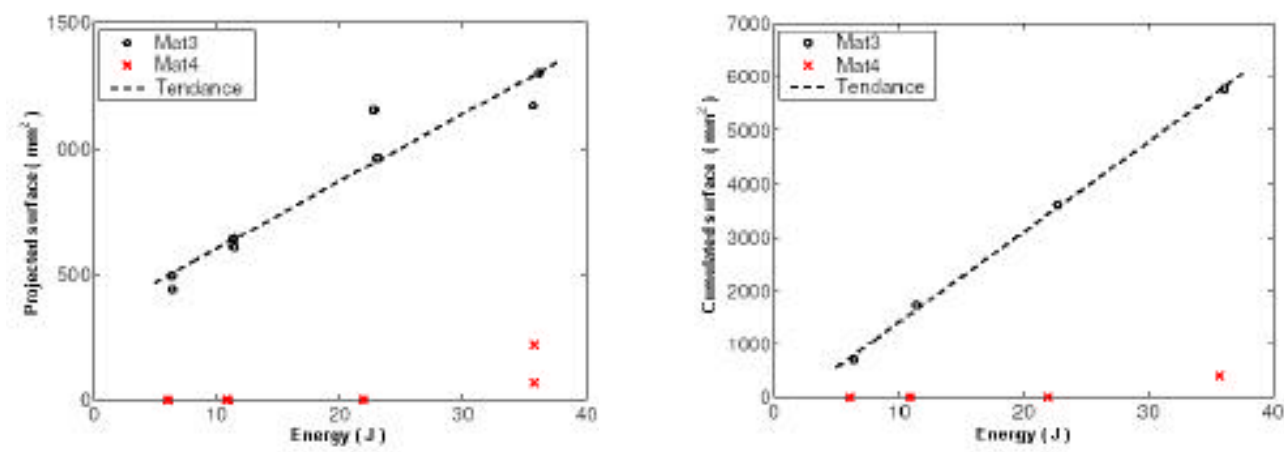

Figure 10. Size effects on the damage during the impacts.

From the four shocks, only those up to $36 \mathrm{~J}$ appeared damaging for Mat4. Figure 9 shows axial cutting of the damaged Mat3 and Mat4 tubes. The damage observed is comparable to those described previously. Figure 10 compares the evolution of the projected and cumulated surface delamination of Mat3 and Mat4 tubes according to incidental energy. Mat4, being more flexible, are damaged significantly less than Mat3 ones for a given energy. It is observed that the response of the structure is dominating on the local behavior. The more flexible the structure the less damage it sustains.

\section{CONCLUSIONS}

The zones damaged on all the cylinders tested present the same aspect. In presence of a dynamic loading, one notes the formation of a volume damaged with a healthy central zone. This volume generally of conical form consists of delaminations on all the interfaces and cracks in all the layers. For the requests with weak incidental energy, the evolution of the projected and cumulated surface delamination versus incidental energy is quasi-linear.

The study of the scale effects shows that each geometry is particularly connected to its manufacture parameters. The load and the maximum displacement as well as the duration of the contact projectile/tube during the impact confirm in a satisfactory way to the Cauchy rules of similarity. On the other hand, a tube of larger scale is damaged in a more significant way. Although the damage is of comparable nature for all the tubes, it is necessary to establish particular laws of similarity in order to predict the damage of a model cylinder from that of the prototype and conversely. Hitherto, it is necessary to test the structures in their final configuration to know their laws of damage precisely. The size effects of the structures are important. The tests show that the response of the structure is of primary importance on the local damage.

\section{REFERENCES}

[1] P.B. Gning, M. Tarfaoui, F. Collombet, L. Riou, P. Davies. Damage development in thick composite tubes under impact loading and influence on implosion pressure: experimental observations. Composites: Part B 36 (2005) 306-318.

[2] K. E. Evans and K. L. Alderson. Low velocity transverse impact of filament-wound pipes: Part 2. residual properties and correlations with impact damage. Composite Structures, 20: 47-52, 1992.

[3] K. L. Alderson and K. E. Evans. Failure mechanisms during the transverse loading of filamentwound pipes under static and low velocity impact conditions. Composites, 23(3): 167-173, 1992.

[4] K. L. Alderson and K. E. Evans. Dynamic analysis of filament wound pipes undergoing low velocity transverse impact. Composites Science and Technology, 45:17-22, 1992.

[5] A. Bulent-Doyum and B. Altay. Detection of low-velocity impact damage in glass/epoxy tubes by penetrant method. Insight, 40(2) :117-121, 1998.

[6] S. J. Kim, N. S. Goo, and T. W. Kim. The effects of curvature on the dynamic response and impact-induced damage in composite laminates. Composites Science and Technology, 57: 763773, 1997. 
[7] K. S. Krishnamuthy, P. Mahajan, and R. K. Mittal. Impact response and damage in laminated composite cylindrical shells. Composites Structures, 59 :15-36, 2003.

[8] L. S. Kistler and A. M. Waas. On the response of curved laminated panels subjected to transverse impact loads. International Journal of Solids and Structures, 36:1311-1327, 1999.

[9] K. E. Evans, K. L. Alderson, and P. R. Marks. Modelling of the transverse loading of filament wound pipes. Computers and Structures, 45(5/6) :1089-1095, 1992.

[10] A. P. Christoforou, S. R. Swanson, S. C. Ventrello, and S. W. Beckwith. Impact damage in carbon/epoxy composite cylinders. Proceedings 32nd International SAMPE Symposium, pages 964-973, 1987.

[11] P. Davies, P. Casari, and L. A. Carlsson. Influence of fibre volume fraction on mode II interlaminar fracture toughness of glass/epoxy using de 4enf specimen. Composites Science and Technology, in press, 2004.

[12] D. Dormegnie, D. Coutellier, E. Deletombe, P. Rozycki, and D. Delsart. Techniques de réduction d'échelle pour l'étude au crash d'un composite stratifié. Proceedings JNC 12, 1: 213-222, 2000.

[13] Y. Qian and S. R. Swanson. An experimental study of scaling rules for impact damage in fiber composites. Journal of Composite Materials, 24 :559-570, May 1990.

[14] B. Bigourdan. Matériaux composites pour module de séparation en eaux profondes. Technical report, Rapport IFREMER, 2002.

[15] F. Pierron and P. Davies. Ring compression test for cylindrical composite mechanical characterization. Fourth European Conference on Composites : Testing and Standardisation, pages 193-202, 1998.

[16] E. Buckingham. On physically similar systems ; illustrations of the use of dimensional equations. Physics Reviews, (4) :345, 1914.

[17] Y. Qian and S. R. Swanson. An experimental study of scaling rules for impact damage in fiber composites. Journal of Composite Materials, 24 :559-570, May 1990. 